\title{
Chapter 5 \\ Empowering Girls Through Sport: A Gender Transformative Approach to Life Skills?
}

\author{
Christina Ting Kwauk
}

\begin{abstract}
From the Pacific Islands to Sub-Saharan Africa, development organizations have positioned sport as an ideal tool for building important life skills that can be transferred from the playing field to day-to-day realities. Sport has also been positioned as a key space for girls' empowerment, especially in contexts where gender norms limit girls' mobility and/or their opportunities to engage in activities stereotyped as being for boys. But an approach that solely focuses on empowering girls through sport by depositing in her useful life skills ignores the structural conditions that have disempowered her in the first place. This chapter examines the gender transformative potential of sport-based life skills programs by exploring the skills that are being targeted, especially for girls' empowerment, by the sport for development (SFD) community. The chapter then examines the implications for our understanding of life skills approaches to gender transformative social change, particularly as it pertains to addressing the conditions that have held girls back.
\end{abstract}

Keywords Life skills · Sport - Gender · Education · Empowerment · Transformation

\section{Acronyms}

SFD Sport for development

SEL Social and emotional learning

KSA Knowledge, skills and attitudes

\section{T. Kwauk $(\bowtie)$}

The Brookings Institution, Washington, DC, USA 


\section{Introduction}

Within the last two decades, there has been a proliferation of sport for development (SFD) programs in the Global South. ${ }^{1}$ In 2013 there were less than 500 registered organizations on the International Platform on Sport and Development; today there are over 1000 (Kwauk, 2014). The growth of SFD has been grounded on two assumptions: (1) that sport is a 'powerful' tool for building important life skills that youth need to participate successfully in social, economic, and political life, and (2) that the skills learned on the playing field can transfer to non-sport contexts like school, home, or the workplace. Indeed, life skills development is often the core education component of any SFD program. However, whether SFD programs are accurately targeting the skills that youth need to achieve improved life outcomes remains to be determined.

Part of the problem faced by SFD organizations and their approaches to life skills is the perennial problem of definition. Much like life skills for other purposes, as indicated by Chaps. 2 and 3 of this volume, the literature on life skills development and sport is centered around studies in the Global North interrogating how life skills are developed through participation in sport (see for example, Holt et al., 2009; Jones \& Lavallee, 2009; Pierce et al., 2016; Theoka et al., 2008). Few studies have actually investigated which life skills are targeted and developed in the context of sport, especially in the context of SFD programs targeting vulnerable populations in the Global South. Indeed, many of the critiques surrounding SFD approaches to life skills development are bolstered by the fact that SFD programs vaguely define what they mean by life skills and are often uncritical in their adoption of the term (Darnell, 2012; Forde, 2014; Hayhurst, 2014). As a result, SFD programs often end up perpetuating the status quo by equipping youth with the skills to successfully navigate a predetermined world around them, rather than to reciprocate by influencing or radically transforming the world around them (Hartmann \& Kwauk, 2011).

This chapter aims to better understand this normative-transformative gap by exploring how SFD programs conceptualize life skills, especially when girls' empowerment is a core desired outcome. Considering nearly half of SFD programs target girls and women (Hancock et al., 2013), it is incumbent upon the field to tackle the question of definition and scope to ensure that programs for girls' empowerment through life skills development are working in a way that is transformative rather than placing the onus of change on the shoulders of girls (Moeller, 2018). This chapter examines a selection of SFD programs that have a strong girls' empowerment focus to understand the possibilities as well as the limitations of current sport-based approaches to girls' life skills development.

\footnotetext{
${ }^{1}$ UNICEF, an early adopter of sport-based approaches to life skills development, defines sport for development as "the use of sport, or any form of physical activity, to provide both children and adults with the opportunity to achieve their full potential through initiatives that promote personal and social development" (UNICEF, 2019, p. 7).
} 


\section{Theoretical Framework}

SFD organizations can be categorized in two ways when it comes to their approaches to education and development: normative and transformative (Hartmann \& Kwauk, 2011). One way includes organizations that take an unintentional and uncritical approach to education through sport-or in this case a normative approach to life skills education through sport-where the theory of change rests on normative assumptions and stereotypes about "the power of sport" to teach skills like teamwork, communication, and goal orientation. Such a dominant approach functions to reproduce neoliberal logics in which the individual, especially those from "at-risk" and "marginalized" populations who may need support on their journey to becoming "model citizens," is expected to bear the brunt of modern government by pulling themselves up by the bootstraps through an instrumentalist, individualistic regimen of self-discipline, self-development, and self-management (Harvey, 2005; Ferguson, 1994; see also DeJaeghere, Chap. 4, this volume). Although the end goal may be to achieve transformation (e.g., the achievement of gender equality, the elimination of gender-based violence, girls' empowerment), a dominant approach operates through the recalibration - or the re-skilling - of the individual, having little do at the end of the day with changing the conditions that put the individual at risk or in marginal positions in society.

Another approach is when organizations take a more transformative approach aimed at altering the conditions of inequality that have marginalized populations in the first place. The theory of change here rests on the notion that sporting contexts create the necessary and sufficient conditions for social change. That is, through a purposeful and critical design, youth must have the opportunity to understand the broader structures of power and privilege in which they are embedded. They must learn to decode the dominant culture with the aim to transform not only their own experiences in the world, but also the world itself. The development of life skills, then, is a process of critical reflection and action that enables individual and collective meaning-making and resistance against hegemonic structures, including especially the recognition of structures and relations of power and how these inform youth experiences and opportunities in life. Such a "radical interventionist" approach does not assume that life skills passively or automatically materialize through participation in sport, however. Rather, it requires that an approach to life skills education entails proactively recognizing, challenging, and transforming structures of inequality, oppression, and exploitation.

Girls' empowerment and gender equality have been popular targets for many SFD organizations since sport for development and peace emerged as a "new" social movement during the Millennium Development Goals era (Kidd, 2008). In earlier work (Hartmann \& Kwauk, 2011), we did not take into consideration how attention to girls' empowerment could at once engender a transformative approach aimed at destabilizing harmful gender stereotypes and relations of power, yet still be firmly rooted in the dominant logics of neoliberalism (Chawansky \& Hayhurst, 2015). That is, SFD programs may promise to liberate women from patriarchal 
oppression only to position them squarely in another, less visible social and economic system of oppression (Forde \& Frisby, 2015; Hayhurst, 2014). Such a confluence of transformation and reproduction remind us that the development project can easily bend a radical agenda toward a neoliberal one.

The conceptual framework that informs this chapter builds upon this earlier work to identify the gap between life skills programs that result in neoliberal outcomes of self-improvement and those that achieve more radical, transformative social change (Kwauk \& Braga, 2017). A starting assumption is that life skills are understood as a combination of knowledge ( $\mathrm{K}$, what one knows), skills ( $\mathrm{S}$, what one has), and attitudes (A, what one believes and values). Together, these form a set of competencies (what one can do) that the individual should be able to activate in any given situation (represented by the image of KSA networks in the brain in Fig. 5.1). If the development of life skills is intended to lead to empowered, liberatory action, the approach must take into consideration the individual's relationship to the sociopolitical contexts and cultural structures in which she is embedded historically, in the present, and in the possible future (represented by the figure of the girl on the right). This relationship comes to bear during the process of translating competencies into action (represented by the long arrow) as her ability to apply life skills in a manner that improves her outcomes is mediated by what we call opportunity structures (represented by the second image in the series) in her environment, like policies, institutions, and social networks. Such opportunity structures, in combination with her sense of agency (represented by the third image in the series) and whether her agency is recognized by others (represented by the back and forth arrow), act as opposing or supporting forces that could inhibit or enable her ability to translate competencies into action.

With this understanding in mind, a dominant approach to girls' life skills education, as also discussed in DeJaeghere's chapter (Chap. 4, this volume), would be characterized as one that focuses solely on depositing (and measuring) knowledge and skills within the individual girl in an effort to put her at a more equal starting point as her more privileged peers within an existing system. In contrast, a transformative approach would attend to the metacognitive elements of equipping girls with the tools to read, decode, and act upon the opportunity structures around her, as well as the sociological elements of building collective resistance against conditions of

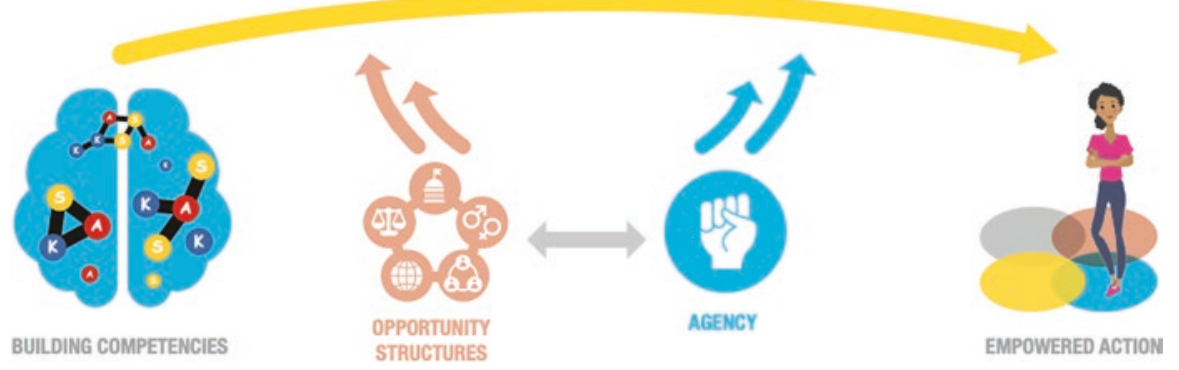

Fig. 5.1 Mediating the translation of competencies to empowered action 
inequality. Drawing upon frameworks discussed in Hartmann and Kwauk (2011) and Kwauk and Braga (2017), this chapter aims to understand whether SFD programs focused on girls' empowerment are contributing to the reproduction or to the transformation of the conditions holding girls back from achieving their full potential.

\section{Methodology}

This paper draws on an analysis of 10 life skills approaches ${ }^{2}$ guiding SFD programs delivered by 7 globally recognized SFD organizations ${ }^{3}$ : ChildFund's Pass It Back, Futuremakers by Standard Chartered, Grassroots Soccer, Moving the Goalposts, Right To Play, Soccer Without Borders, and Women Win. Each SFD organization's life skills approach was analyzed in two steps.

First, to understand the breadth of skills being targeted and to compare different constructions of skills across different programs, skills were given one or more codes from the Explore SEL coding scheme. ${ }^{4}$ For this particular analysis, the 177 "benchmarks" for each of the six domains (cognitive, emotion, social, values, perspectives, and identity) identified in the Explore SEL tools were used to code skills mentioned explicitly in the SFD programs' life skills documents. ${ }^{5}$ In the event that the organization did not have an actual life skills framework, program curricula and/ or monitoring and evaluation tools were used instead. When coding the latter, only explicitly stated learning objectives, learning outcomes, or behavioral descriptors were coded; lesson overviews and activity descriptions were excluded due to time limitations. A focus on stated objectives or outcomes-where a life skills framework was absent-helped to ensure parameters were in place to conservatively interpret organizational intent with regard to targeted skills.

In the first analysis, some skills were not codable using the Taxonomy's coding scheme. This was a limitation that fortuitously provided an opportunity for a secondary inductive analysis of the remaining life skills. Specifically, the "leftover,"

\footnotetext{
${ }^{2}$ For simplicity, the term life skills approach will be used herein to refer to the programmatic documents included in this study, including life skills frameworks, program curricula, program descriptions, theories of change or logic models, and monitoring and evaluation tools, depending on what was made available by the organization.

${ }^{3}$ For the purposes of this analysis, I will use the term SFD organization when referencing the seven organizations and programs included in this study, whether or not the organization formally identifies this way.

${ }^{4}$ See Chap. 3 (Brush et al., this volume) for an overview of the Explore SEL project.

${ }^{5}$ See http://exploresel.gse.harvard.edu/compare-terms/ for the Taxonomy Project's benchmarks used to code life skills in this analysis. For ease of analysis, this paper adopts the Taxonomy Project's conceptualization of life skills as being defined by domains of socioemotional learning and codable by observable behavioral benchmarks. As such, this may miss other domains of life skills, including knowledge, skills, and attitudes important for catalyzing social change, which we discuss in Kwauk and Braga (2017).
} 
un-codable skills were analyzed to generate new sub-domain categories of skills that are conceptualized more towards gender transformative outcomes for girls.

Second, to understand the normative and transformative elements of the life skills approaches, a more in-depth analysis was conducted of all the targeted skills identified in the first analysis. Targeted skills were coded as being normative, transformative, or context-dependent based on the description of the skill given by the life skills document. Skills were coded as normative if the outcome associated with it could be characterized as putting the girl at a more equal starting point as her male peers in a pre-existing system or enabling a girl to function more successfully within existing social structures. An example of a normative skill would be "listening to what others have to say without interrupting them." Such skills could be interpreted as coming from a dominant approach to girls' life skills education where even a girls' empowerment approach could be instrumentalized toward achieving a more individualistic, neoliberal agenda of self-improvement rather than serve as a mechanism for transforming relations of power.

In contrast, skills were coded as transformative if the outcome associated with it could be characterized as equipping girls with the tools to read, decode, and act upon the opportunity structures or existing social structures around her in ways that enable her to fulfill her own desired outcome(s) rather than what is expected of her because of her gender. For example, "identify how society's definition of girlhood leads to oppression of women and girls" or "navigating power and gender relationships" are skills that could be interpreted as coming from a more transformative approach, attending more to the metacognitive elements of "reading" one's world to be better positioned to transform it.

Some descriptions of skills were less clear in terms of their normative or transformative intention. For instance, "having a support system of people who model positive behavior and support you" could be interpreted as building a network of peers that help you ascribe to socially acceptable norms of good behavior (a normative outcome) or as building allies to engage in collective resistance against conditions of inequality. Such ambiguous skills were coded as "context-dependent."

Table 5.1 provides a brief overview of the life skills programs included in this analysis, all of which use either a sport-based or play-based curriculum to deliver life skills education. Programs were selected for inclusion based on convenience of access to both program materials (e.g. has a substantive online presence) and program staff, as well as purposefully to ensure geographic diversity and diversity of targeted outcome (e.g. economic empowerment, gender equality, and improved sexual and reproductive health, education, or employment opportunities) (see Table 5.2 for an overview of program targeted outcomes). Curricular or program documents were collected by the author from either the organization's website or through personal communication with program staff.

All programs either target girls specifically, place a special emphasis on the participation of marginalized, vulnerable, or disadvantaged girls, or take special measures to ensure girls are recruited to participate in equal numbers as boys and that programs are delivered in gender-sensitive and inclusive ways. Right To Play extends its focus on gender beyond girls, looking to also promote "positive 


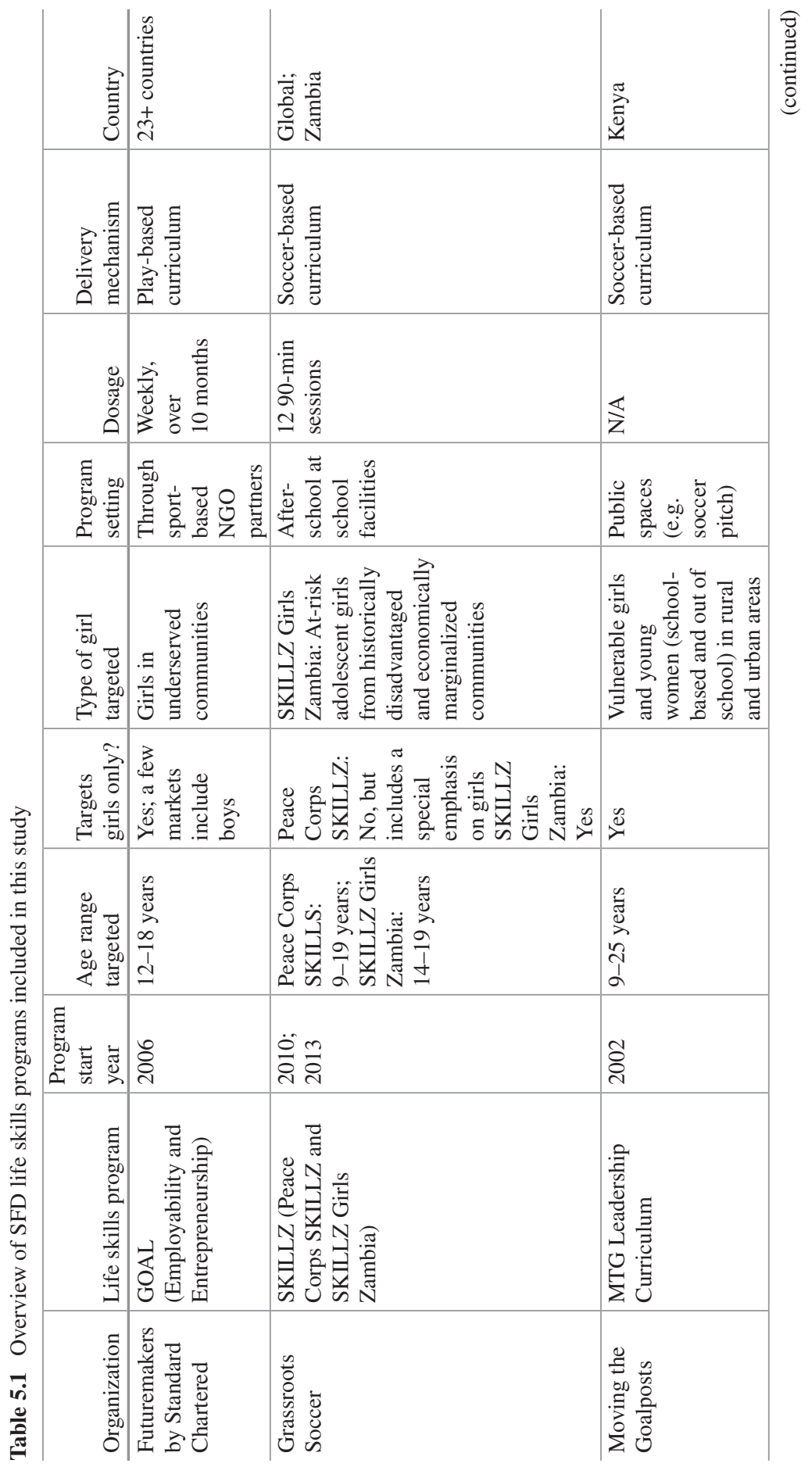




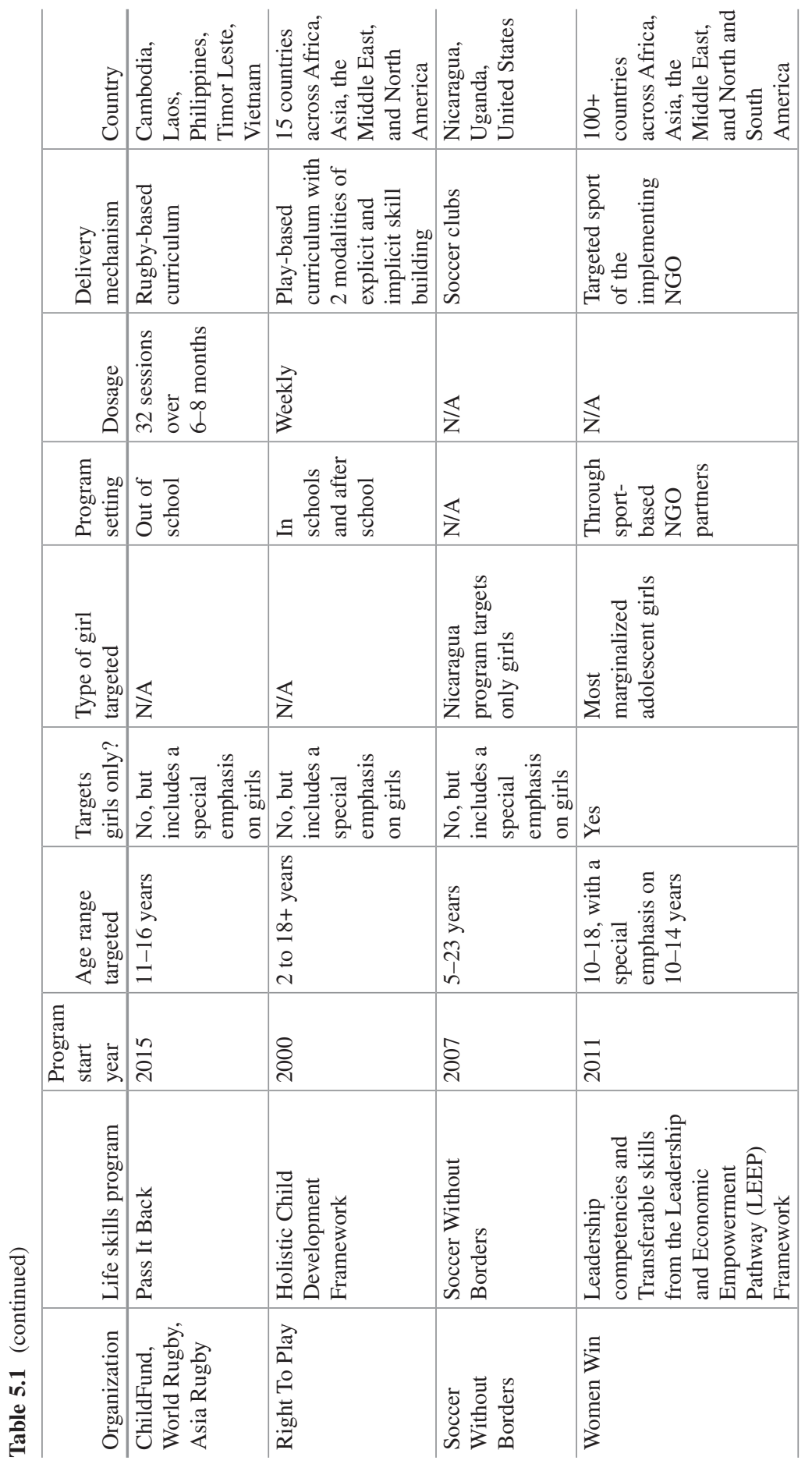


Table 5.2 Targeted outcomes of sport-based life skills education programs

\begin{tabular}{l|l}
\hline Life skills program & Targeted outcome areas \\
\hline Standard Chartered's GOAL Program & Health (hygiene, sexual and reproductive health, and \\
menstrual hygiene management) \\
Self-confidence (communications and valuing what it \\
means to "be a girl") \\
Empowerment (rights, freedom from violence, access \\
to resources/institutions and social networks in the \\
community) \\
Economic empowerment (financial literacy, \\
employment, and entrepreneurship)
\end{tabular}

Grassroots Soccer (Peace Corps SKILLZ and Girls SKILLZ Zambia)

Assets (increased health knowledge and the confidence to use it)

Access (increased uptake of high-quality health services)

Adherence (adherence to medical treatment, therapy, and healthy behaviors)

Moving the Goalposts Leadership
Curriculum

Child Fund Pass It Back

Right To Play's Holistic Child

Development Framework

\section{Education (scholarships)}

Sexual and reproductive health and rights

Livelihoods (skills for financial independence)

Rugby knowledge and sport skills

Leadership development (voice, confidence, vision, ability to drive change, resilience)

Safety (healthy and positive relationships, awareness and prevention of violence, taking action and providing support)

Planning for the future (planning and setting goals, risks and positive behaviors, understanding community resources)

Understanding gender (gender roles, rights, violence, peer pressure)

Quality education

Gender equality

Child protection

Peaceful communities

Health and well-being

Growth (skills that break barriers, build girls'

confidence and voice as leaders)

Inclusion (build teams that feel like family)

Personal success (help young women reach their goals; access a community of supportive peers and mentors)

Women Win (Leadership Framework and LEEP Transferable Skills Framework)
Decreased gender-based violence

Improved sexual and reproductive health and rights (including service access)

Increased girls' economic empowerment (education and entrepreneurial or career development) 
masculinities by building boys' life skills around communication, expressing emotions and resolving conflicts peacefully" (Right To Play [RTP], 2018, p. 2). In contrast, Moving the Goalposts, while not explicitly involving boys, does recognize the need to engage boys in equal partnerships and participation with girls through friendly co-ed matches. Their approach, however, views such engagement as opportunities for girls to learn to negotiate public spaces that boys and men often dominate. Engaging boys, then, is less about intentionally shifting boys' gender attitudes and more about providing girls safe spaces to practice "claiming what is theirs" (Moving the Goalpost [MTG], 2019, p. 7). As such, girls' empowerment was either an explicitly stated goal or component of the program (e.g. Standard Chartered's GOAL Program includes a module on girls' empowerment), or an implicit goal as described by the organization's mission and objectives (e.g. Right To Play's website, righttoplay.com, states that "Play saves lives [...] It gives girls the power to say no to unwanted sex, and make healthy decisions about their bodies and their futures.").

\section{Findings: From Normative to Transformative Approaches}

How have SFD programs approached girls' empowerment through life skills? To answer this, this section provides an overview of the breadth of skills targeted by sport-based life skills programs and suggests these programs may not differ much from non-sport programs that have leaned heavily toward a prosocial, selfimprovement paradigm. If we look strictly at how SFD programs describe their targeted skills, the dominant normative approach of "fix the girl, not the system" is quite pervasive. Nevertheless, there is transformative potential as well in some of these constructions, of which programs should be made aware in order to help pivot the remainder of their targeted life skills toward more gender transformative outcomes.

\section{Normative Constructions of Life Skills}

Other studies have demonstrated that (non-sport) life skills programs place a heavy emphasis on social and interpersonal skills as well as on the acquisition of knowledge (c.f. Dupuy et al., 2018). This analysis confirms this trend, finding a heavy emphasis on skills within the Social and Emotion domains (constituting together approximately $43 \%$ of codable targeted skills), as well as a heavy emphasis on skills that fell under the Cognitive domain (approximately $26 \%$ of codable skills) (see Fig. 5.2). The cognitive emphasis can be partly explained by the conflation of knowledge with "life skills." This is not surprising, as many non-sport-based life skills programs define and target life skills according to the sector of the organization from which the program originates (Dupuy et al., 2018). As a result, learning 


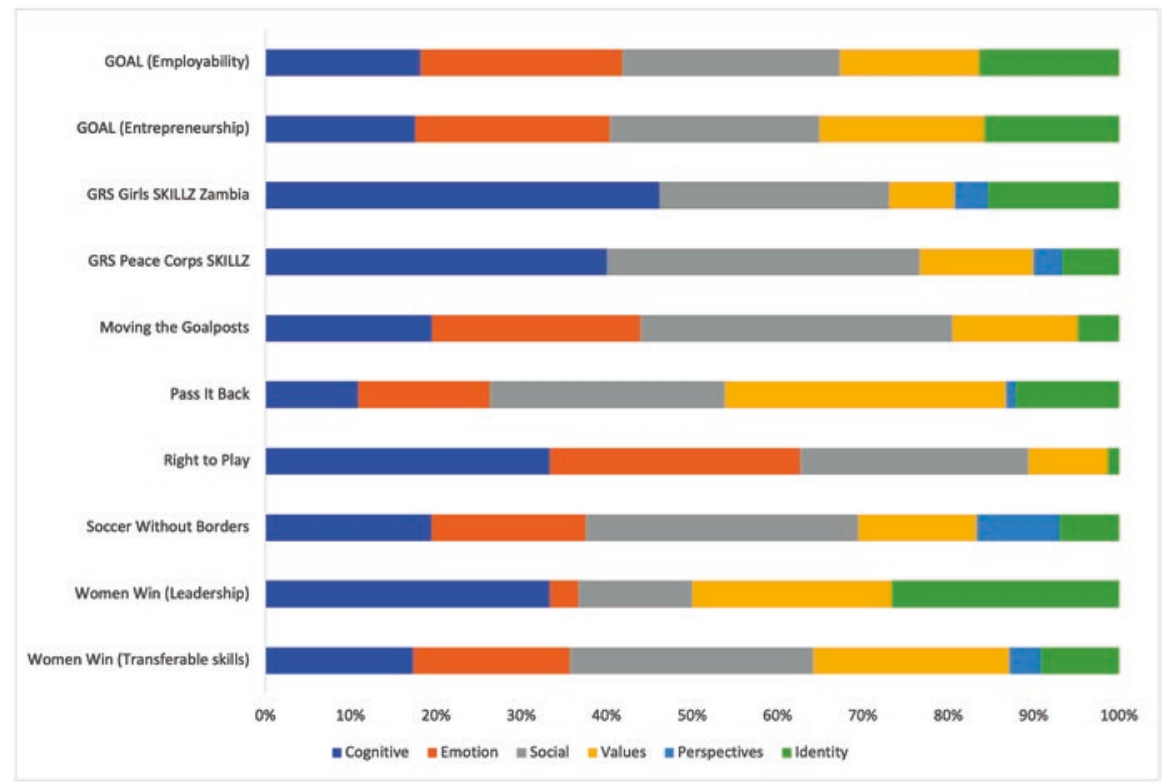

Fig. 5.2 Relative values of SFD programs' targeted life skills, by domain

objectives are heavily tied to content areas (or subject knowledge) core to the organization's mission rather than to the acquisition of skills. To illustrate, the GOAL programs were spearheaded by Standard Chartered and have a strong focus on financial literacy; their approach toward life skills tends to focus on acquiring knowledge of banking services and effective business practices, and the development of cognitive skills like goal setting and problem solving. The SKILLZ programs reflects Grassroots Soccer's focus on adolescent sexual and reproductive health; their approach toward life skills tends to focus on gaining knowledge about HIV/AIDS and other sexually transmitted diseases and building cognitive skills like planning and consequential thinking.

When it comes to interpersonal skills under the Social and Emotion domains, sport-based life skills programs may be missing an important opportunity to orient their programs toward more transformative ends. For instance, programs rarely target skills that could help increase girls' understanding of social cues. In fact, Social skills that fall under "understanding social cues" constitute only $9 \%$ of coded skills and dealt primarily with being able to interpret others' body language and tone of voice in order to recognize hostile motivations or friendly intentions and to be able to respond appropriately. Such an approach to understanding social cues is more closely associated with emotional intelligence rather than with strengthening girls' abilities to read her context (e.g. power cues or social opportunities) as a means of determining how to translate, transfer, and apply life skills to different life situations (Kwauk \& Braga, 2017). 
Instead, SFD life skills frameworks place a heavy emphasis on prosocial, cooperative behavior-comprising $88 \%$ of the skills coded under the Social domain. This includes skills to engage more effectively in teamwork, in building positive relationships, and to demonstrate respect for others. Without coupling such prosocial skills with, for instance, attention towards non-violent "anti-social" skills of a more civil disobedience nature (e.g. standing up for oneself against peer pressure, engaging in conflict and debate in order to achieve justice or fairness), such a heavy emphasis on cooperative behavior could lead to normative behavioral outcomes where girls are taught to behave within pre-existing social norms and expectations rather than to question social structures that may perpetuate oppressive gender norms.

Indeed, research on transformative learning suggests that life skills programs should pay more attention to the intrapersonal domains of Values, Perspectives, and Identity. Such domains may be critically important for laying the foundations for the kind of "epistemic learning" needed to change the way people think about and exist in the world and, therefore, how they perceive and interact with the world (O'Brien, 2018; Sterling, 2010). This would include actively deconstructing assumptions, beliefs, and values held about gender and gender roles, and the consequent gendered practices and structures that shape girls' and boys' experiences and influence their beliefs and interactions with each other.

However, in the analysis of codable skills (those targeted skills that could be coded using the Explore SEL coding scheme), it appears as though SFD programs are not paying attention to these domains. To illustrate, on average, only $2 \%$ of targeted life skills were coded under the Perspectives domain (e.g. openness to new ideas and new experiences). While the Values and Identity domains fared a little better (17\% and $12 \%$ on average, respectively), the discrepancy in attention across domains (see Figure 5.2) suggest that there is not a clear consensus-or awareness-around the importance of these domains for life skills development. Consequently, the high attention to the Cognitive, Emotion, and Social domains and the scant attention paid to the Values, Perspectives, and Identities domains means that sport-based life skills programs are giving girls ample opportunity to develop skills to think and feel better and to be better with others, while giving girls little opportunity to critically reflect upon, make new meaning of, and resist social structures and social practices that may be stacking the cards against them.

\section{Context-Dependent Constructions of Life Skills}

Figure 5.3 provides a clearer illustration of the extent to which SFD programs approach life skills in a normative versus transformative way. Of all the targeted skills $(\mathrm{N}=359)$ identified for this analysis, $74 \%$ were constructed in a normative manner-that is, intended to improve girls' self-development, self-management, and/or ability to function successfully in society. In stark contrast, only $4 \%$ of targeted skills were constructed in a transformative way-that is, aimed at enabling 


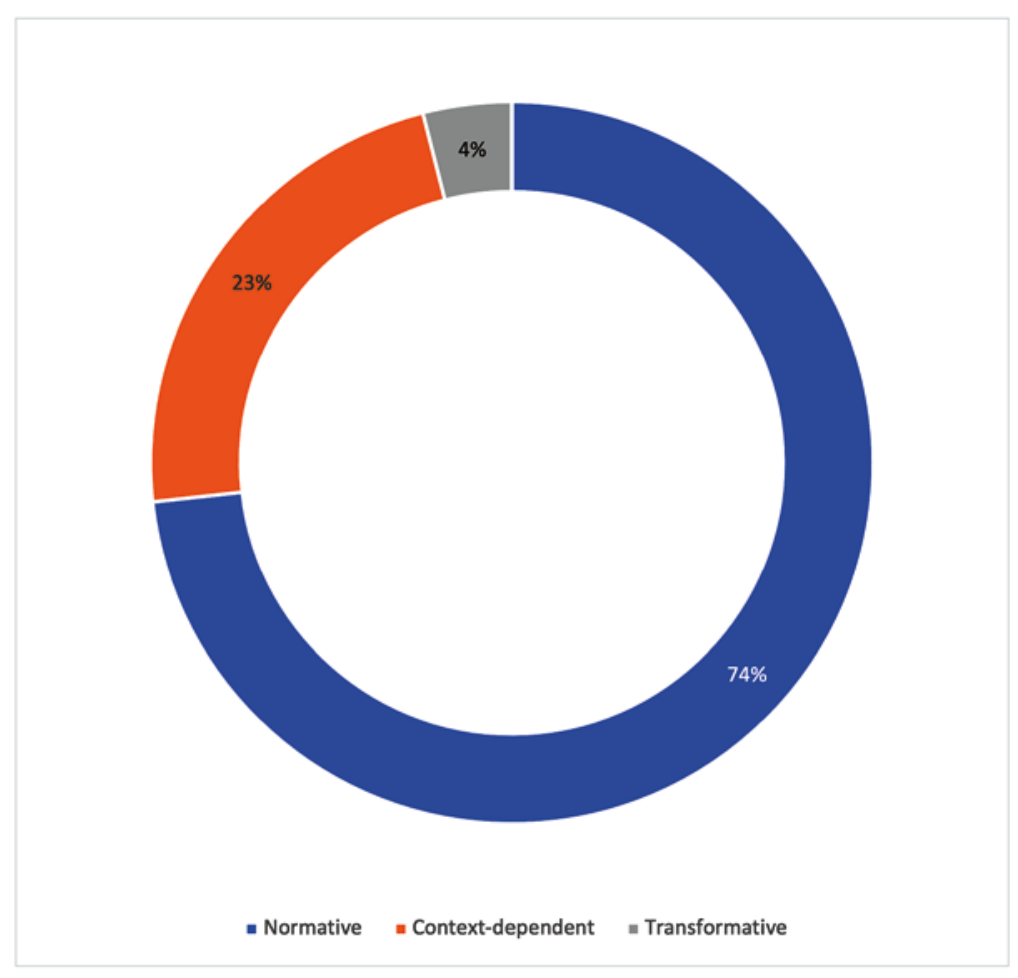

Fig. 5.3 Coded skills and their orientation to development and change

girls to alter the conditions of inequality and discrimination created on the basis of her gender.

Such a lopsided distribution suggests that individualistic, neoliberal logics about life skills dominate SFD programs. However, nearly a quarter of targeted skills were constructed in ways that were difficult to determine whether they were wholly normative or wholly transformative. Rather, these skills could be classified as contextdependent, depending on how programs contextualize and operationalize these targeted skills through program activities. More importantly, the outcomes of these skills are highly dependent on whether program staff emphasize their application as a means to become immune and resilient to sexist and patriarchal structures, or to challenge and resist them.

To illustrate, one type of skill or outcome area that SFD life skills frameworks targeted was the ability to access community services-in a sense, to embolden and empower girls to avail themselves of their right to services that can improve their health and well-being. In short, leveraging opportunity structures. Such a degree of awareness and resourcefulness could be normative - that is, seeking to put girls on equal footing as others in society. However, if combined with an emphasis on challenging discriminatory policies or exclusionary practices, this skill could be 
interpreted to be transformative. Another example is "seeing the possibility for change." Depending on how facilitators help girls to define change and the intended outcomes from that change, such a perspective could either help to norm girls and their aspirations to a socially defined "good life," or to help girls materialize a future of their own choosing.

While some programs' targeted skills contained more context-dependent skills than others-and some programs contained more normative approaches to skills than others - the span of normative to transformative approaches to life skills is a reminder that SFD programs are not monolithic. While the majority of their targeted life skills are aimed at equipping girls to better fit and successfully navigate their world, there is cause for optimism in the nuance that programs can be more radical. Specifically, there is room for programs to pivot toward enabling girls to see, challenge, and transform their world.

\section{Toward More Transformative Possibilities}

Based on a thematic analysis of the "uncodable" targeted life skills, this section proposes new sub-domains of skills that help to illustrate how life skills can be contextualized within a more transformative, feminist agenda (see Table 5.3). As mentioned earlier, the terms used for the new sub-domains and the descriptions of the observable skills were developed through an inductive analysis of the uncodable skills and learning objectives described in the curricular and framework documents.

For starters, under the Social domain, new sub-domains like "engaging difference" could work to counter the more normative skills that promote the socialization of marginalized groups into the dominant culture. "Reciprocity and solidarity," which captures the spirit of "giving back" that several programs emphasized, could ensure that skills are targeted that help to amplify or cascade individual empowerment to the collective level, building on the notion that structural change does not happen alone but rather through collective social change. Similarly, "partnerships and coalitions" could help distribute the onus of change from the individual girl to the collective. This new sub-domain emerges out of SFD programs' heavy emphasis on developing role models and peer mentors.

To address the need for more attention to intrapersonal skills that are foundational to transformative learning, this analysis generated five new sub-domains under the Perspectives and Identity domains that are not only targeted at reading the world but also actively engaging it. Two of these sub-domains (resistance and power) were particularly prominent in the list of uncodable life skills. This includes things like being aware of how gender norms can be oppressive, understanding ways to help others break free of gender stereotypes, increasing understanding about how power manifests in relationships, and how to make joint decisions about things that affect more than oneself. Such attention to issues of gender and power have been demonstrated in the literature to be important for improving girls' reproductive health outcomes (Haberland, 2015). Integrating such skills into our 
Table 5.3 New sub-domains for a more gender transformative life skills taxonomy

\begin{tabular}{|c|c|c|}
\hline $\begin{array}{l}\text { Domain of } \\
\text { SEL }\end{array}$ & New sub-domain & Observable skill \\
\hline \multirow[t]{3}{*}{ Social } & $\begin{array}{l}\text { Engaging } \\
\text { difference }\end{array}$ & $\begin{array}{l}\text { Communicates and engages effectively with others from } \\
\text { different backgrounds (e.g., gender, sexual orientation, } \\
\text { religion, caste, race, etc.) } \\
\text { Recognizes one's own value and experiences, and the unique } \\
\text { contributions that one can make in a group as a result of } \\
\text { one's difference, and vice versa (e.g., that others are unique } \\
\text { and have valuable contributions to make as a result) }\end{array}$ \\
\hline & $\begin{array}{l}\text { Reciprocity and } \\
\text { solidarity }\end{array}$ & $\begin{array}{l}\text { Understands the importance of "passing it back" to the } \\
\text { community (e.g., shares new knowledge and skills with } \\
\text { others) } \\
\text { Shows solidarity with those who have given them support or } \\
\text { invested in their growth and development }\end{array}$ \\
\hline & $\begin{array}{l}\text { Partnerships and } \\
\text { coalitions }\end{array}$ & $\begin{array}{l}\text { Can recognize good qualities (e.g., leadership, positive } \\
\text { influence) in others } \\
\text { Can recognize how a relationship (e.g., between mentee and } \\
\text { mentor) could be helpful and/or strategic } \\
\text { Can build social assets and social networks that can be } \\
\text { beneficial in their life }\end{array}$ \\
\hline \multirow[t]{3}{*}{ Perspectives } & Resourcefulness & $\begin{array}{l}\text { Aware of barriers to access to key resources, services, and } \\
\text { institutions in the community and can identify strategies for } \\
\text { overcoming such barriers } \\
\text { Can map out opportunities, both present and in the future }\end{array}$ \\
\hline & Resistance & $\begin{array}{l}\text { Understand social expectations and their sources (e.g., } \\
\text { family, friends, media, etc.) } \\
\text { Aware of how dominant, hegemonic scripts (e.g., traditional } \\
\text { gender norms, patriarchy) can limit people from achieving } \\
\text { their full potential } \\
\text { Can identify ways to push back against hegemony and write } \\
\text { new, liberating and empowering social scripts }\end{array}$ \\
\hline & Power & $\begin{array}{l}\text { Understands and can map power dynamics within social } \\
\text { units (e.g., intimate partnerships, the household, community) } \\
\text { Can effectively, strategically, and safely negotiate unequal } \\
\text { power dynamics with others, especially those with more } \\
\text { "power over" or "power to" } \\
\text { Shares decision making power with an intimate partner and/ } \\
\text { or with others }\end{array}$ \\
\hline \multirow[t]{2}{*}{ Identity } & Self-awareness & $\begin{array}{l}\text { Recognizes how others may be perceiving their } \\
\text { communication, expression of emotions, or body language } \\
\text { Can identify and articulate one's skills, strengths, and } \\
\text { talents, as well as weaknesses and areas for development to } \\
\text { others }\end{array}$ \\
\hline & Self-advocacy & $\begin{array}{l}\text { Aware of their rights, beliefs, needs, and accomplishments, } \\
\text { and are willing and motivated to speak up and to speak out } \\
\text { in defense of or in promotion of these }\end{array}$ \\
\hline
\end{tabular}


understanding of life skills would help to ensure that more programs actively think about these competencies in their design.

To address the absence of "anti-social" skills of a civil disobedience nature, this analysis generated several sub-domains focused on resisting and challenging social structures. This includes a self-advocacy sub-domain under the Identity domain to ensure that girls develop the ability to speak up and speak out on behalf of themselves, their rights, their needs, their beliefs, and their accomplishments and successes. While the Taxonomy Project includes attention to whether the individual stands up for him or herself (and others) in the face of peer pressure or bullying, this focus does not get at the underlying intention of many SFD programs to combat negative self-image and to give girls voice by granting them permission to own up to their achievements, beliefs, and rights in contexts where they are taught early on that they are not of value or worth because of their gender. In a way, these new subdomains capture what could be described as "empowerment skills," at least in terms of the behaviors that one could expect of an "empowered" (read: outspoken) girl.

While these 8 new sub-domains synthesize what was left uncoded after the initial analysis of SFD life skills frameworks, existing skills within the remaining domains of Cognitive, Emotion, and Values could also be made more gender transformative. For example, one could argue that the Cognitive domain's critical thinking subdomain could include new benchmarks that capture skills like the ability to understand and recognize unequal power relations or to hear what is "unspoken," as well as to include additional sub-domains like strategic thinking. The Values domain could include attention toward ethical uses of power that do not violate the rights of others, or a focus on understanding and taking action toward challenging harmful (gender, racial, class, religious, ability) stereotypes, or even more foundational beliefs in the importance of solidarity, social justice, gender equality, and the equal value of all human beings. The possibilities are endless. What this analysis of SFD approaches to life skills education for girls demonstrates is how contextualizing life skills within a critical feminist agenda could help shift dominant understandings of life skills toward more transformative ends.

\section{Limitations and Opportunities for Further Insight}

There were three limitations inherent to this analysis. The first limitation was technical: the analysis was limited by the scope of the documents that could be included. Because not every organization included in this study has a life skills framework guiding their life skills program, other documents like coaching guides, program curriculum, and monitoring and evaluation tools were included instead. Generalizations about program intent and targeted skills should thus be understood with this caveat. In addition, whether program implementation is aligned with these documents or whether targeted skills are actually developed are matters beyond the focus of this analysis on the conceptualization of life skills by program documents. 
The second limitation was one of interpretation. Because documents other than life skills frameworks were included, I had to take the liberty of interpreting targeted skills based on an analysis of learning objectives, which were oftentimes couched in the language of knowledge areas rather than skills, abilities, or competencies. Programs that vaguely define life skills also frequently misidentify targeted skills in program design and measurement outcomes (see Kwauk \& Braga, 2017). Due to the terminology challenge around life skills, which Murphy-Graham and Cohen (Chap. 2, this volume) explore, I used the Explore SEL as a way to arrive at a common understanding of the life skills targeted by different SFD programs. As such, my interpretation of the life skills identified or described in the SFD programs' documents may not be what the program designers would have interpreted ${ }^{6}$

The third, and more interesting limitation, was conceptual: the analysis was at once enabled yet constrained by the Explore SEL coding scheme, pointing to how life skills frameworks have not yet dealt with issues of normativity and transformativity when it comes to the orientation of life skills towards development and social change. While the coding scheme allowed disparate approaches to life skills development to be compared based on how skills, behaviors, and desired outcomes were described, it was in examining the uncodable skills that the lack of attention to life skills for social transformation came into stark relief. Such a gap highlights the tendency for life skills to be conceptualized at the individual (self-improvement) level, rather than in relation to the social structures and social relationships that have marginalized certain communities in the first place.

This gap reveals several issues worth investigating further. The most immediate opportunity is to investigate how a critical feminist lens may generate new (sub) domains of skills, and/or lead existing definitions and descriptions of skills to be revised toward a more social and gender transformative vision. For example, the prosocial, cooperative behavior of "Follows classroom/institution/society rules and expectations (norms, directions) and exhibits appropriate behavior for context" could be read as promoting the reproduction of normative behaviors deemed socially acceptable by the dominant culture, putting marginalized groups into further positions of disadvantage. Furthermore, such a targeted behavior ignores whether obedience of rules by marginalized groups (who are often the target of life skills education)

\footnotetext{
${ }^{6}$ This was particularly the case for "skills" coded across the Cognitive domain that were described in terms of knowledge areas by the program document. For example, the document used to analyze Grassroots Soccer's Girls SKILLZ Zambia life skills framework included a learning objective like "Identify how society's definition of girlhood leads to oppression of women and girls," which was coded as "Identifies and understands the existence and nature of problems," a critical thinking skill under the Cognitive domain. The learning objective "Describe contraceptive use as joint decision between both partners" was coded as "Recognizes multiple sides of an issue and/or understands multiple perspectives" (a critical thinking skill under the Cognitive domain). And, the objective "Describe positive self-talk and how it can be used to build your confidence" was double coded as "Shifts attention from one task, aspect, or perspective to another" (a cognitive flexibility skill under the Cognitive domain) and "Expresses confidence in oneself and one's ability to improve or succeed" (a self-efficacy/growth mindset skill under the Identity domain).
} 
for the sake of coexisting peacefully with others (often the dominant culture) creates the necessary and sufficient conditions for the empowerment of the former.

Another issue is how to balance attention across knowledge areas and targeted skills if we are to conceptualize life skills as a combination of what one knows (knowledge), has (skills), and believes and values (attitudes). The analysis illuminates how programs have conceptualized-or at least how they have described in their documents-life skills education as the acquisition of content-specific knowledge like financial literacy, sexual and reproductive health, or how to find (or create) a job. While some programs take a feminist approach and target knowledge areas especially important for gender empowerment (e.g. recognizing how gender roles create a "man box" or "woman box" of gender stereotyped behavior), SFD programs are missing an important opportunity to target competencies that can transform knowledge of saving and borrowing money, knowledge of modern contraceptives, or knowledge of business resource acquisition and allocation, for example, into double-edged swords that help girls fundamentally alter financial, health, and corporate systems of oppression.

A final area that needs more investigation is the relationship between life skills development and agency — a key component mediating the translation of life skills into empowered action (Kwauk \& Braga, 2017). Although the SFD programs analyzed here all have an eye toward empowering the girl to be a more autonomous, agentic self, such framing follows an individualistic conceptualization of agency as a skill to be developed in itself, a capacity that one can possess, and a sense of possibility and self-worth that can be deposited into a girl in a safe and nurturing setting. However, as explained elsewhere (ibid.), agency is both individual and relational, iterative and dialogical. A girl's sense of agency depends as much on whether others recognize her as an autonomous individual-what DeJaeghere (Chap. 4, this volume) extends to a discussion of dignity-as on whether she has had the opportunity to successfully exercise her agency in the past. However, conceptualizations of agency by sport-based life skills programs tend to ignore the relational achievement of agency, missing an important opportunity to address the achievement of agency in a more transformative way.

\section{Conclusion}

According to this analysis of 10 sport-based life skills approaches, SFD programs do not appear to be wholly neoliberal nor wholly transformative. Rather, their approach to girls' empowerment through life skills development is a complicated patchwork. Some aspects of their approaches frame life skills development from a normative paradigm, especially when it comes to framing issues of health for "at risk" youth (e.g. sexual and reproductive health, HIV/AIDS). Other aspects position SFD programs as coming from a transformative approach, especially when it comes to issues of gender and identity (e.g. pushing against gender stereotypes, exercising one's voice), or taking into account mediating factors (e.g. community services, 
boys and men). It is in the midst of this patchwork, however, where critical, postcolonial, and transnational feminist critiques of life skills should be brought to bear in order to help ensure that radical interventions around gender transformative social change do not get cloaked in individualism or co-opted by the unintentional reproduction of dominant neoliberal logics.

Overall, SFD programs appear to be no different than non-sport-based life skills programs in terms of the heavy attention to knowledge areas and socioemotional skills-although this analysis also found a heavy emphasis on cognitive skills as well. More interesting, however, are the insights gained by looking at the skills targeted by SFD programs that could not be coded according to the Explore SEL current coding scheme. In short, the coding scheme-like dominant frameworks of life skills - is gender blind, missing an important opportunity to serve as a tool to help program designers and implementers conceptualize life skills in a more transformative way. Concepts like self-advocacy, power negotiation, power mapping, resistance against hegemony, and recognizing social assets and strategic relationships would not only help to give the Explore SEL tools a gender lens, but also help push the field of life skills education beyond its neoliberal underpinnings toward a more radical interventionist approach that equips youth with the tools to both read the world and to act on that world.

SFD programs are a unique platform for life skills development. However, programs must be designed more intentionally in order to leverage the necessary and sufficient conditions created by sport: they need to pay greater attention to gender transformative skills, pivot context-dependent skills toward more transformative ends, and re-examine the neoliberal logics undergirding presently normative skills. Similar to Hartmann and Kwauk (2011), this chapter concludes that it is vital to recognize the contributions of SFD programs' sporting and non-sporting components to open opportunities for girls to engage in critical reflexive practice around gender transformative mindsets and behaviors. Only then can SFD programs begin to disrupt social structures of oppression and inequality that have held girls back from realizing their full potential in the first place.

Acknowledgements The author would like to thank Natalie Starr Wyss for her invaluable research support, as well as Grassroots Soccer, Moving the Goalposts, Naz Foundation, Pass It Back, Right to Play, Soccer Without Borders, Standard Chartered, and Women Win for sharing their life skills curricula, frameworks, theories of change, as well as their programmatic insights for this analysis. An additional thanks goes to Women Win for facilitating introductions to a number of organizations included in this analysis.

\section{References}

Chawansky, M., \& Hayhurst, L. M. C. (2015). Girls, international development and the politics of sport: Introduction. Sport in Society, 18(8), 877-881. https://doi.org/10.1080/1743043 7.2014.997587

Darnell, S. (2012). Sport for development and peace: A critical sociology. Bloomsbury Academic. 
Dupuy, K., Bezu, S., Knudsen, A., Halvorsen, S., Kwauk, C., Braga, A., \& Kim, H. (2018). Life skills in non-formal contexts for adolescent girls in developing countries. CMI Report, 5. Chr. Michelson Institute.

Ferguson, J. (1994). The anti-politics machine: 'Development', depoliticization, and bureaucratic power in Lesotho. University of Minnesota Press.

Forde, S. D. (2014). Look after yourself, or look after one another? An analysis of life skills in sport for development and peace HIV prevention curriculum. Sociology of Sport Journal, 31, 287-303. https://doi.org/10.1123/ssj.2013-0103

Forde, S. D., \& Frisby, W. (2015). Just be empowered: How girls are represented in a sport for development and peace HIV/AIDS prevention manual. Sport in Society, 18(8), 882-894. https://doi.org/10.1080/17430437.2014.997579

Haberland, N. (2015). The case for addressing gender and power in sexuality and HIV education: A comprehensive review of evaluation studies. International Perspectives on Sexual and Reproductive Health, 41(1), 31-42. https://doi.org/10.1363/4103115

Hancock, M. G., Lyras, A., \& Ha, J. (2013). Sport for development programmes for girls and women: A global assessment. Journal of Sport for Development, 1(1), 15-24.

Hartmann, D., \& Kwauk, C. (2011). Sport and development: An overview, critique, and reconstruction. Journal of Sport and Social Issues, 35(3), 284-305. https://doi. org/10.1177/0193723511416986

Harvey, D. (2005). A brief history of neoliberalism. Oxford University Press.

Hayhurst, L. M. C. (2014). The 'Girl Effect' and martial arts: Social entrepreneurship and sport, gender and development in Uganda. Gender, Place and Culture, 21(3), 297-315. https://doi. org/10.1080/0966369X.2013.802674

Holt, N. L., Tamminen, K. A., Tink, L. N., \& Black, D. E. (2009). An interpretive analysis of life skills associated with sport participation. Qualitative Research in Sport and Exercise, 1(2), 160-175. https://doi.org/10.1080/19398440902909017

Jones, M. I., \& Lavallee, D. (2009). Exploring perceived life skills development and participation in sport. Qualitative Research in Sport and Exercise, 1(1), 36-50. https://doi. org/10.1080/19398440802567931

Kidd, B. (2008). A new social movement: Sport for development and peace. Sport in Society, 11, 370-380. https://doi.org/10.1080/17430430802019268

Kwauk, C. (2014). Playing for the future: Sport and the production of healthy bodies in policy and practice. Doctoral dissertation, University of Minnesota. University of Minnesota Digital Conservancy. http://hdl.handle.net/11299/181761

Kwauk, C., \& Braga, A. (2017). Translating competencies to empowered action: A framework for linking girls' life skills education to social change. Brookings Institution.

Moeller, K. (2018). The gender effect: Capitalism, feminism, and the corporate politics of development. University of California Press.

Moving the Goalposts. (2019). MTG model - Step by step. https://mtgk.org/

O'Brien, K. (2018). Is the 1.5C target possible? Exploring the three spheres of transformation. Current Opinion in Environmental Sustainability, 31, 153-160. https://doi.org/10.1016/j. cosust.2018.04.010

Pierce, S., Gould, D., \& Camiré, M. (2016). Definition and model of life skills transfer. International Review of Sport and Exercise Psychology, 10(1), 186-211. https://doi.org/10.108 0/1750984X.2016.1199727

Right to Play. (2018). Gender equality policy. https://righttoplaydiag107.blob.core.windows.net/ rtp-media/documents/Gender_Equality_Policy_RTP_2018.pdf

Soccer Without Borders. (n.d.). Organization website. http://soccerwithoutborders.org

Sterling, S. (2010). Transformative learning and sustainability: Sketching the conceptual ground. Learning and Teaching in Higher Education, 5, 17-33. 
Theoka, C., Danish, S., Hodge, K., Heke, I., \& Forneris, T. (2008). Enhancing life skills through sport for children and youth. In N. L. Holt (Ed.), Positive youth development through sport (pp. 71-81). Routledge.

UNICEF. (2019). Getting into the game: Understanding the evidence for child-focused sport for development. UNICEF Office of Research - Innocenti.

Open Access This chapter is licensed under the terms of the Creative Commons Attribution 4.0 International License (http://creativecommons.org/licenses/by/4.0/), which permits use, sharing, adaptation, distribution and reproduction in any medium or format, as long as you give appropriate credit to the original author(s) and the source, provide a link to the Creative Commons license and indicate if changes were made.

The images or other third party material in this chapter are included in the chapter's Creative Commons license, unless indicated otherwise in a credit line to the material. If material is not included in the chapter's Creative Commons license and your intended use is not permitted by statutory regulation or exceeds the permitted use, you will need to obtain permission directly from the copyright holder. 